\title{
Challenges for the cataract surgeon treating people with dementia: a qualitative study exploring anesthetic choices
}

This article was published in the following Dove Press journal:

Clinical Ophthalmology

26 September 2014

Number of times this article has been viewed

\author{
Joanna Mary Jefferis ${ }^{1-3}$ \\ Michael Patrick Clarke ${ }^{1,3}$ \\ John-Paul Taylor ${ }^{2}$ \\ Katie Rhian Brittain ${ }^{4}$
}

'Newcastle Eye Centre, Royal Victoria Infirmary, ${ }^{2}$ Institute for Ageing and Health, ${ }^{3}$ Institute of Neurosciences, ${ }^{4}$ Institute of Health and Society, Newcastle University, Newcastle upon Tyne, UK
Correspondence: Joanna Mary Jefferis Clinical Ageing Research Unit, Campus for Ageing and Vitality, Newcastle University, Newcastle upon Tyne, NE4 5PL, UK

Tel +44 I9I $248 \quad 1297$

Fax +44 I9| 248 I250

Email joanna.jefferis@ncl.ac.uk
Background: In light of the growing number of people with dementia and age-related cataract, as well as changing anesthetic practices for cataract surgery, this study aimed to explore the experiences of cataract surgeons in managing patients with dementia and making anesthetic decisions.

Methods: This was a qualitative study using semistructured interviews with senior cataract surgeons from two centers in England. Fourteen surgeons were interviewed, and a thematic approach informed by grounded theory was used for the analysis.

Results: Choice of anesthesia for people with dementia was a central theme arising from the data. Surgeons varied in their thresholds for using general anesthesia. Decisions about suitability for local anesthesia were limited by time constraints and generally made rapidly and based on instinct; dementia was not always apparent at the point of preassessment. Surgeons used a variety of topical, sub-Tenon's, and sharp needle blocks for people with dementia. Surgeons discussed techniques to help patients tolerate local anesthesia, such as clear communication, a primary nurse, hand-holding, and support from an anesthetist. However, within our sample, some surgeons had had negative experiences of operating on people with dementia, where an incorrect judgment had been made that they could tolerate local anesthetic cataract surgery.

Conclusion: This study highlights the differing practices of cataract surgeons when making anesthetic choices for people with dementia and the challenges they face. In order to avoid the situation of a patient with dementia becoming distressed during awake surgery, increased time at preassessment and anesthetic support may be beneficial.

Keywords: dementia, cataract extraction, anesthesiology, qualitative research

\section{Introduction}

Dementia and visual impairment due to cataract are common age-related problems amongst older people, ${ }^{1-3}$ and particularly amongst those in residential care. ${ }^{4-7}$ With the growing number of older people in our population, ${ }^{8}$ the number of people with coexistent dementia and cataract is likely to rise. ${ }^{9}$

Since the early 1980s, there has been a marked shift from performing most cataract surgeries under general anesthesia to performing them under local anesthesia. ${ }^{10,11}$ The vast majority of cataract surgeries worldwide are now carried out under local anesthesia, ${ }^{12}$ but there are widely differing preferences for local anesthetic techniques both between and within different countries and centers, with no single local anesthetic technique being a recognized "best practice". However, there is a trend away from using sharp needle blocks and a growth in the number of people using purely topical anesthetic. ${ }^{13}$ Along with this, there has been a diminishing role for the ophthalmic 
anesthetist, with an increasing number of surgeons happy to operate without an anesthetist. ${ }^{14}$

Changing trends in anesthetic practice open up new issues when it comes to considering patients with dementia in whom there may be significant challenges with operating under local anesthesia. Indications for a general anesthetic include communication difficulties and difficulty complying with instructions, which are often the case for people with dementia. ${ }^{15}$ However, general anesthesia can increase the risk of postoperative delirium following cataract surgery, ${ }^{16} \mathrm{a}$ particular concern in those with dementia. Furthermore, there are some concerns that general anesthesia can be associated with more permanent cognitive decline, but whilst this seems to be the case for major surgery, ${ }^{17}$ it has not been shown to be true for cataract surgery. ${ }^{18}$

Given the changes in anesthetic practices for cataract surgery seen over the last generation, and the growing number of older people in our population, it is important to consider afresh anesthetic practices for people with dementia undergoing cataract surgery. Qualitative research can be useful in exploring complex, multidimensional issues such as this, and can help us to understand such issues without erasing differing perspectives. ${ }^{19}$ As qualitative research is not hypothesis-driven, it also enables us to explore areas of research that we are unaware of a priori and may otherwise be neglected. ${ }^{20}$ The aim of this study was to explore the current anesthetic practices of cataract surgeons treating people with dementia and to highlight any areas where additional support or further hypothesis-driven research is required.

\section{Materials and methods}

\section{Participants}

Participants were eligible for inclusion if they were independent (consultant or senior staff grade) ophthalmologists performing regular cataract surgeries at one of two eye units in the North East of England. Purposive sampling was used in order to obtain a sample with a spectrum of experience and demographics. Furthermore, as themes emerged, participants were selected in order to build on these developing themes, so theoretical sampling was undertaken. ${ }^{21}$ Fourteen interviews were carried out (seven participants from each center) and sampling was stopped when data saturation was reached. Data saturation was defined as when no new themes or ideas emerged from three consecutive interviews, and this decision was made by discussions between JMJ and KRB. ${ }^{22}$

This study followed the tenets of the Declaration of Helsinki and informed, written consent was obtained from all participants. We discussed the study with our local research ethics committee who exempted the research from requiring ethical approval on the basis that all participants were health care workers. Local research and development approval was obtained.

\section{Interviews}

Interviews were semistructured using open-ended questions and an interview schedule with broad question categories and prompts. The interview aimed to cover all aspects about cataract surgery for people with dementia. Key topics were initially identified from a priori questions and literature searching but modified as new topics and themes emerged from the data collection. All the interviews were carried out by JMJ who had worked as a junior ophthalmology trainee in one of the units, and so was known to the participants from that unit. Interviews were carried out in a location chosen by the participant (generally the participant's own office). The interviews were 24-43 (mean 30) minutes in length. The interviews were digitally recorded and then transcribed.

\section{Analysis}

The analysis was based on thematic analysis and was strongly influenced by the techniques of grounded theory. ${ }^{21,23,24}$ Data analysis proceeded alongside data collection and began after the first interview. Familiarization with the data was achieved by listening to the audio recordings and reading and rereading the transcripts. Constant comparison methods were used to make comparisons both within single interviews and between interviews. ${ }^{21,25}$ Initial coding of the data was carried out using detailed codes, and as the analysis progressed, a coding framework was produced with codes grouped together in themes. The coding framework was continually modified as analysis progressed. As new codes were added, previously coded interviews were checked for examples of the new code. NVivo9 was used to organize data and codes. A "one sheet of paper" (OSOP) technique ${ }^{26}$ was used to rearrange the data according to themes. The OSOP included a summary of all the issues within a code, with the identification numbers of relevant respondents next to them. Quotes in the text are labeled by center (A or B) and an individual participant number (02-15); participants have not been identified as male or female or by subspecialty interest in order to protect their anonymity.

\section{Results}

The participants interviewed represented a wide range of experience and expertise. One of the surgeons was a senior 
staff grade ophthalmologist and the rest were consultants. Cataract caseloads varied from about 100 cases per year to over 2,000 cases per year. Most surgeons had a subspecialty interest as well as cataract surgery, and these included glaucoma, cornea, vitreoretinal surgery, neuroophthalmology, oculoplastics, pediatrics, strabismus, and medical retina. There was a mixture of male $(n=11)$ and female $(n=3)$ ophthalmologists, some of whom had been consultants for many years and some were relatively new consultants (range 3-29 years).

Anesthetic choice was seen as a principal issue when undertaking surgery on people with dementia, and was discussed by all the cataract surgeons. It was recognized that changes in anesthetic practice had had a significant impact on the care of people with dementia.

"It always used to be of course that people had a general anesthetic so it didn't really matter if they were demented or not, from an operational point of view." (A.02)

\section{General anesthesia}

There were differing opinions amongst surgeons when it came to the use of general anesthesia. Some were clearly quite concerned about the potential complications of general anesthesia in a group of older people who are likely to have comorbidities. They felt it best to avoid general anesthesia because of risks to the mental health and general health of the patient and increase in the length of stay in hospital.

"Well yes, I mean I don't know the ins and outs of general anesthetic in dementia but I am sure that it doesn't help. And they generally have lots of other medical problems as well and you know it is obviously much more of a significant event and I think you need to be much more convinced that there is a good chance of some benefit." (A.03)

Others went on to say that, in patients who do need a general anesthetic, one would need to think very hard about whether the cataract surgery is still in the patient's best interests. They felt that in order to justify a general anesthetic for cataract surgery in a patient with dementia they would have to have very significant visual disability.

\footnotetext{
"I would think on average, I would tend to feel that a cataract would have to be rather worse in a severely demented patient to justify putting them through surgery than it would be in a mentally competent patient, because it is going to cause some disruption to the patient's life. If you do have to do a general anesthesia then it's another ball game altogether and the potential gains may not be so great." (A.11)
}

There was also a feeling that using a general anesthesia made consent more complex, particularly in a patient lacking the capacity to consent, where one would have to be sure that the surgery is in the patient's best interests.

"If you ask me about people who need a general anesthetic, so that they really are unable to comprehend what was going on; I don't think I have ever operated on anyone that bad. I think for the simple reason in order to give them a general anesthetic, there is so much more involved, you know, there is a possibility they won't wake up, there's taking away their consciousness in the procedure, and the fact they couldn't consent to that. For them to be that unwell, really they wouldn't be able to see anything, you know, in terms of everyday life. And one would almost have to be holding them, forcing them in a sense to give them an anesthetic." (A.05)

However, other surgeons used general anesthesia more commonly in people with dementia. They felt that the risk that a patient with dementia may become distressed in the middle of an operation leading to a potentially serious, sight-threatening complication often outweighed the risks of general anesthesia. These surgeons tended to work in close collaboration with anesthetists when making decisions about general anesthesia; they also had regular access to a general anesthetic list, which was not the case for all the cataract surgeons.

"Is it worth taking a small risk with a general anesthetic in order to avoid a bigger risk of them sitting up half way through the surgery and having a dropped nucleus?" (A.04)

Whilst some surgeons felt that reducing the stress for themselves by carrying out cataract surgery under general anesthetic for people with dementia was sensible, others appeared to enjoy the challenge of operating on people with dementia under local anesthetic.

"It is difficult to secure the lasting co-operation of a patient with significant cognitive impairment in cataract surgery under local anesthetic. It increases the risks to them, to some extent to the surgeon's coronary arteries as well.” (B.07)

"Well I feel it's positive if you can give an elderly, often frail patient to complete a cataract extraction under topical anesthesia rather than giving them a helluva wallop by giving them a general anesthetic. Every single time it is an achievement to do that." (A.02)

In the UK it is not usual practice to carry out bilateral, simultaneous cataract surgeries because although the risk 
of endophthalmitis is small, to get this bilaterally would be devastating for the patient. However, some surgeons felt that when carrying out a general anesthetic in a patient with dementia then it might be reasonable to consider bilateral surgeries. Others avoided bilateral surgeries, with one surgeon reasoning that people with dementia might be at a higher risk of endophthalmitis than people without dementia.

\section{Local anesthesia}

Local anesthetic preferences amongst the surgeons reflected the fact that UK cataract surgeons vary greatly in their local anesthetic choices, even within centers. ${ }^{13,14}$ Interestingly, most surgeons interviewed here did not change from their usual anesthetic practice when operating on people with dementia. Indeed, many surgeons had reasons why they felt that their usual practice was also best for people with cognitive difficulties and some were quite emphatic about their choice of local anesthesia being the best for people with dementia. Table 1 shows the contrasting positive and negative attitudes that surgeons had to either topical or regional block anesthetics. The surgeons who did sometimes alter their anesthetic practice for people with dementia did so depending on their assessment of the patient, tending towards a block if they felt that the patient would find it difficult to keep their eye still during the operation or follow simple instructions.

"If you get somebody and spread their lids apart and get them to look at something then they are often going to be okay. Whereas if when you open their lids they screw their eye up then you know it's not worth going for topical and I tend to give them blocks." (B.10)

\section{Ways to make a local anesthetic work}

Surgeons discussed various ways of increasing the chance of a patient with dementia tolerating cataract surgery under

Table I Contrasting views of local anesthetic techniques

\begin{tabular}{|c|c|c|}
\hline & Sharp needle or sub-Tenon's blocks & Topical anesthesia \\
\hline $\begin{array}{l}\text { Positive } \\
\text { attitudes }\end{array}$ & $\begin{array}{l}\text { "But, I do have a relatively low threshold for giving } \\
\text { a block, because it can save you a lot of problems } \\
\text { and stress intra-operatively, and it is one less thing } \\
\text { for you to worry about if you know the patient } \\
\text { can't move their eye." (B.I4) } \\
\text { "I always give them an injection anesthetic, so } \\
\text { I give them a retrobulbar anesthetic; which } \\
\text { although it is not particularly uncomfortable, it is } \\
\text { enough of an assault to them, if you like, to know } \\
\text { that they can tolerate lying still and following } \\
\text { instructions." (A.05) } \\
\text { "The real trial is when you give them a local } \\
\text { anesthetic and I am not a particularly keen topical } \\
\text { anesthetic cataract surgeon anyway, I think the } \\
\text { vast majority of my locals are sub-Tenon LA and } \\
\text { I would certainly want to give a sub-Tenon LA in } \\
\text { this sort of patient." (A.I I) }\end{array}$ & $\begin{array}{l}\text { "It is a rare, rare patient really that I wouldn't do under } \\
\text { topical. ... If you are happy with the movement and } \\
\text { you know that you can cope, then it is easier because } \\
\text { you don't have to pad the eye and the patient is not in } \\
\text { theater for a longer time and stuff like that." (A.08) } \\
\text { "I think elderly people have a much higher tolerance to } \\
\text { pain and discomfort than other people. I do topical all } \\
\text { the time." (A.08) } \\
\text { "...but when I moved over to topical with sub- } \\
\text { conjunctival added then one found that the process } \\
\text { became effectively painless from the patients point } \\
\text { of view and it became possible to do local anesthetic } \\
\text { procedures on patients with mild to moderate dementia } \\
\text { who were of the correct personality type." (A.02) } \\
\text { "It's surprising what you can do under topical, but you } \\
\text { know patients often have a fear of needles and stuff, and } \\
\text { often are really happy that you are going to do topical. } \\
\text { You know, we do a lot of topical anesthesia, you know } \\
\text { when you can manage." (B.II) } \\
\text { "The other thing is if they're topical and you can talk } \\
\text { to them and you can get them to look where you want } \\
\text { them to look." (B.I } 2 \text { ) }\end{array}$ \\
\hline $\begin{array}{l}\text { Negative } \\
\text { attitudes }\end{array}$ & $\begin{array}{l}\text { "I just think it just complicates the matter, you } \\
\text { know more things to be done. You want the } \\
\text { whole process to be as compressed as possible, so } \\
\text { you know, if you give a block outside, something } \\
\text { could cause a hemorrhage or, you know, patient's } \\
\text { having seen something being done at that point in } \\
\text { time, because often the peribulbar block, at that } \\
\text { instant does hurt a bit.” (A.08) } \\
\text { “...coming at somebody even if it's only drops and } \\
\text { doing their sub-Tenon's, it's still cutting at them, } \\
\text { and they don't like when they see somebody } \\
\text { poking!” (B.I2) }\end{array}$ & $\begin{array}{l}\text { "I wouldn't personally do a topical local anesthetic on } \\
\text { somebody who has got dementia. I think it is unfair on } \\
\text { them as well as being more difficult for me." (A.04) } \\
\text { "But if I am doing it under topical and there is an } \\
\text { anesthetist, you know, in the next room who hasn't } \\
\text { blocked the patient because they are going to do a } \\
\text { topical and the eye's moving all over the place you are } \\
\text { sort of thinking 'Why didn't we block it? Why didn't we } \\
\text { block it?' And you get yourself agitated about it if you } \\
\text { aren't careful." (B.I5) }\end{array}$ \\
\hline
\end{tabular}


local anesthesia. Central to this was making a correct judgment about the patient and their ability to tolerate a local anesthetic in the first instance. Regardless of choice of local anesthetic, there was a common theme that patient selection was important. However, due to the time pressures on surgeons in the cataract preassessment clinic, judgments about a patient's mental state were generally made rapidly and based on experience and observation of the patient's behavior. None of the surgeons used formal measures to assess mental state. This surgeon talked about how he makes judgments of a patient's mental state preoperatively by using eye contact:

"I look at them, you know, make eye contact, total eye contact, and then I ask them, and then I subconsciously simultaneously try to make some judgment as to, you know, is this person okay or not okay?" (A.08)

Sometimes these instinct-based methods of assessing mental state resulted in missing the fact that a person had dementia at the preassessment stage.

"Certainly ones that have seemed quite rational in clinic and able to understand and manage and cope, and then in the anesthetic room and theater you are getting much more repetitive questioning of questions that you have already answered and you sort of think, hang on a minute, we've just discussed that and maybe there is a memory problem, that wasn't particularly apparent when we had the discussion in clinic." (A.03)

Surgeons reported that if patients were able to tolerate the preassessment process, which includes measurement of lens power with an intraocular lens master, slit-lamp examination, and pressure measurements, then these were good signs that they would tolerate a local anesthetic, regardless of their level of cognitive impairment. Knowledge of previous procedures that the patient has undergone such as venipuncture might be helpful in assessing whether they are likely to tolerate local anesthetic cataract surgery.

"Generally if people cooperate with examination and lying while you put drops in, they are probably going to be okay, and if you've managed to do an IOL master scan, they are generally probably going to be okay to have local anesthetic cataract surgery.” (B.10)

During the surgery, with the patient awake, surgeons talked about various methods that they employed to help the patient tolerate the operation. These included: bringing a family member up to the local anesthetic room with them, or even in some circumstances into the operating theater; talking to the patient and giving them constant reassurance throughout the operation; taking care to position the patient as comfortably as possible; and having supportive nursing staff who can hold a hand and talk reassuringly to the patient. Some surgeons found having an anesthetist present, even if they were using a local anesthetic, is useful so that the anesthetist can be in charge of the patient's well-being whilst the surgeon can concentrate on the surgery itself.

"So even if you are not doing a GA it might be a good idea to have somebody responsible for the patient's well-being while you are concentrating on the eye because it is difficult to do both sometimes." (A.11)

Another surgeon talked about the usefulness of having a local anesthetic list supported by an anesthetist once a week, and it was on this list that any patients suffering from dementia would be listed. Anesthetic support also enabled some surgeons to consider the use of sedation, and a number of surgeons would, with the help of an anesthetist, use a small amount of sedation with the local anesthetic. However, others were wary of giving sedation, as it can have the opposite of the desired effect, putting the patient at more significant risk than a general anesthetic.

"I know the dangers of sedation as well, you know, patients can still aspirate and things when they're under sedation and also if you have got someone who is potentially going to be a bit unsettled during the surgery then they are going to need deeper sedation and I think, I would give them a GA I think." (B.13)

\section{Wrong judgments}

A number of the surgeons talked about reasonably rare occasions where a wrong judgment had been made about the anesthetic type for a patient with dementia. In these cases, an operation had been scheduled with local anesthetic but it became clear that the patient would not tolerate an operation under local anesthetic. Surgeons stressed the need to recognize this earlier, as the further through the operation one proceeds, the more difficult it is to abandon the procedure. In some of these cases surgery was abandoned and a general anesthetic was scheduled for another day; in other cases, the surgeon continued with a procedure that could become distressing for everyone involved.

\footnotetext{
"The patient went to sit up on the table and I had already started and I had done the capsulorhexis, and I was actually phaco-ing, and she sat up on the table. And I said well
} 
I can't leave it like this, so we actually had to physically hold her down, which not - I wouldn't do and I wouldn't recommend it and that was, she did okay, but it was dreadful, I mean she was screaming and roaring ... and it was dreadful.” (B.12)

"She was a lady who had dementia, and was prepped and draped and I had just made the incision, so I had done one incision into the eye with the keratome and then she became very, very agitated and I just sensed that this could go rapidly downhill ... so we ended up having to cancel." (B.14)

\section{Discussion}

This study gives insight into some of the particular issues in making anesthetic choices for people with dementia undergoing cataract surgery. To our knowledge, nobody has previously described the decisions that cataract surgeons make about anesthesia for people with dementia or explored the reasons behind these decisions. With an ageing population, where both cataract and dementia rates are rising, ${ }^{9}$ and with changing practices surrounding anesthesia for cataract surgery, these issues are important to investigate. This work highlights the complexity surrounding anesthesia for people with dementia undergoing cataract surgery and the need to open up a formal discussion around best care for this patient group.

Differing practices surrounding the use of general anesthesia are likely influenced by factors such as access to a general anesthetic list and experience. For example, a surgeon with a subspecialty interest in oculoplastics or strabismus might have regular access to a general anesthetic list (principally for non-cataract surgery) and so readily list someone with dementia for general anesthetic surgery. Conversely, someone with no regular general anesthetic list with a high cataract case load and extensive experience of complex cataract cases under local anesthesia might feel more confident to carry out the surgery under local anesthetic.

Again, differing preferences over local anesthetic techniques (see Table 1) are probably influenced by the experience and "comfort zone" of the surgeon. Most surgeons used the local anesthetic technique that they were most familiar and comfortable with when it came to what could be otherwise somewhat stressful surgery. As the number of surgeons using topical anesthetic alone for cataract surgery increases, it may be that surgeons become increasingly comfortable using this for patients with dementia also.

Thankfully, instances of wrong judgments were rare, but these highly distressing experiences for patient and surgeon would ideally be a never-event. The time-limited, instinct-based assessment of patients preoperatively and the drive to have more cataract lists without any anesthetic support ${ }^{14}$ perhaps need to be addressed in order to make sure that these events do not happen.

This study is not without its limitations. Qualitative interviews are often best conducted by someone who has little or no specialist knowledge of the field and is unfamiliar with the literature..$^{27,28}$ The interviewer here (JMJ) was an ophthalmology trainee who has previously reviewed the literature on some of these issues. ${ }^{9}$ For this reason, analysis of the data could not be purely inductive as it naturally drew on previous ideas and understanding of the field of study. All the data are based on interview data, so the results represent surgeons' accounts of phenomena, rather than the phenomena themselves. Only cataract surgeons were interviewed; to widen the understanding of the issues discussed, it would be useful to interview anesthetists, specialist nurses, patients, and carers; however, this was felt to be beyond the scope of this study. Caution needs to be exercised when generalizing the results of qualitative research, ${ }^{28}$ but we think this study highlights important issues that are transferrable to cataract surgeons in a variety of settings.

\section{Conclusion}

Choices surrounding anesthesia in people with dementia have the potential to cause considerable stress for surgeons and (at least in surgeons' views) patients, particularly when incorrect judgments are made. Cataract surgeons have widely varying practices and preferences when it comes to anesthetic choices for people with dementia. If using a local anesthetic, surgeons generally try to use the anesthetic technique that they are most familiar with for what might be an otherwise difficult operation. A number of surgeons were happy to carry out surgery for people with dementia under topical anesthesia. Time pressures in the preassessment clinic mean that assessment of mental state preoperatively is generally rapid and instinct-based, and dementia can go unnoticed. Increased time at preassessment might be beneficial for patients with known dementia. It is also important not to ignore the role of the ophthalmic anesthetist, who can help ensure the well-being of a patient with dementia even during local anesthesia. This research highlights the need to open up formal discussions on best practice for people with dementia undergoing cataract surgery.

\section{Acknowledgments}

We would like to thank Mrs Julie Nattrass for her help with the transcriptions, Mr David Steel for providing assistance with recruitment, and all the participants who gave freely of their time and expert knowledge. This work was supported 
by a National Institute of Health Research doctoral research fellowship award to JMJ. The views expressed in this publication are those of the authors and not necessarily those of the National Health Service, the National Institute of Health Research, or the Department of Health.

\section{Author contributions}

JMJ designed the study, recruited participants, gathered the data, analyzed the data, and drafted the paper; MPC and JPT conceived the study; KRB provided supervision throughout the study, and assisted with analysis and drafting the paper. All authors contributed toward data analysis, drafting and revising the paper and agree to be accountable for all aspects of the work.

\section{Disclosure}

The authors report that they have no competing interests in this work.

\section{References}

1. Ferri CP, Prince M, Brayne C, et al. Global prevalence of dementia: a Delphi consensus study. Lancet. 2005;366:2112-2117.

2. Congdon N, Vingerling JR, Klein BE, et al. Prevalence of cataract and pseudophakia/aphakia among adults in the United States. Arch Ophthalmol. 2004;122:487-494.

3. Tan AG, Wang JJ, Rochtchina E, Mitchell P. Comparison of age-specific cataract prevalence in two population based surveys 6 years apart. $B M C$ Ophthalmol. 2006;6:17.

4. Van Newkirk M, Weih L, McCarty C, Stanislavsky Y, Keeffe J, Taylor HR. Visual impairment and eye diseases in elderly institutionalised Australians. Ophthalmology. 2000;107:2203-2208.

5. Tielsch JM, Javitt JC, Coleman A, Katz J, Sommer A. The prevalence of blindness and visual impairment among nursing home residents in Baltimore. N Engl J Med. 1995;332:1205-1209.

6. Owsley C, McGwin G, Scilley K, Meek GC, Dyer A, Seker D. The visual status of older persons residing in nursing homes. Arch Ophthalmol. 2007;125:925-930.

7. Taiel-Sartral M, Nounou P, Rea C, et al. Acuité visuelle et pathologie oculaire chez le sujet âgé résidant en maison de retraite: étude orléanaise sur 219 personnes [Visual acuity and ocular disease in geriatric nursing homes. Study in 219 elderly people in France]. J Fr Ophtalmol. 1999;22:431-437. French.

8. Oeppen J, Vaupel JW. Demography. Broken limits to life expectancy. Science. 2002;296:1029-1031

9. Jefferis JM, Mosimann UP, Clarke MP. Cataract and cognitive impairment: a review of the literature. Br J Ophthalmol. 2011;95:17-23.
10. Sindhu K, Colrain I, Buttery R, Wise G. A survey of local anesthesia use in cataract surgery in Australia. Aust N Z J Ophthalmol. 1991;19:43-48.

11. Eke T, Thompson JR. The National Survey of Local Anesthesia for Ocular Surgery. I. Survey methodology and current practice. Eye. 1999;13 Pt 2:189-195.

12. Eichel R, Goldberg I. Anesthesia techniques for cataract surgery: a survey of delegates to the Congress of the International Council of Ophthalmology, 2002. Clin Experiment Ophthalmol. 2005;33: 469-472.

13. El-Hindy N, Johnston RL, Jaycock P, et al. The Cataract National Dataset electronic multi-centre audit of 55567 operations: anesthetic techniques and complications. Eye. 2009;23:50-55.

14. Chandradeva K, Nangalia V, Hugkulstone CE. Role of the anesthetist during cataract surgery under local anesthesia in the UK: a national survey. Br J Anaesth. 2010;104:577-581.

15. Kallio H, Rosenberg PH. Advances in ophthalmic regional anesthesia. Best Pract Res Clin Anaesthesiol. 2005;19:215-227.

16. Milstein A, Pollack A, Kleinman G, Barak Y. Confusion/delirium following cataract surgery: an incidence study of 1-year duration. Int Psychogeriatr. 2002;14:301-306.

17. Silbert B, Evered L, Scott DA. Cognitive decline in the elderly: is anesthesia implicated? Best Pract Res Clin Anaesthesiol. 2011;25: 379-393.

18. Karhunen U, Jonn G. A comparison of memory function following local and general anesthesia for extraction of senile cataract. Acta Anesthesiol Scand. 1982;26:291-296.

19. Kuper A, Reeves S, Levinson W. An introduction to reading and appraising qualitative research. BMJ. 2008;337:a288-a288.

20. Pope C, Mays N. Reaching the parts other methods cannot reach: an introduction to qualitative methods in health and health services research. BMJ. 1995;311:42-45.

21. Glaser BG, Strauss AL. The Discovery of Grounded Theory: Strategies for Qualitative Research. Chicago, IL, USA: Aldine Publishing Co; 1967.

22. Francis JJ, Johnston M, Robertson C, et al. What is an adequate sample size? Operationalising data saturation for theory-based interview studies. Psychol Health. 2010;25:1229-1245.

23. Strauss AL, Corbin JM. Basics of Qualitative Research. Techniques and Procedures for Developing Grounded Theory. 2nd ed. London, UK: Sage; 1998.

24. Charmaz K. Constructing Grounded Theory: A Practical Guide through Qualitative Analysis. London, UK: Sage; 2006.

25. Boeije $\mathrm{H}$. A purposeful approach to the constant comparative method in the analysis of qualitative interviews. Qual Quant. 2002;36: 391-409.

26. Ziebland S, McPherson A. Making sense of qualitative data analysis: an introduction with illustrations from DIPEx (personal experiences of health and illness). Med Educ. 2006;40:405-414.

27. Kennedy TJ, Lingard LA. Making sense of grounded theory in medical education. Med Educ. 2006;40:101-108.

28. Green J, Thorogood N. Qualitative Methods for Health Research. 2nd ed. London, UK: Sage; 2009.
Clinical Ophthalmology

\section{Publish your work in this journal}

Clinical Ophthalmology is an international, peer-reviewed journa covering all subspecialties within ophthalmology. Key topics include: Optometry; Visual science; Pharmacology and drug therapy in eye diseases; Basic Sciences; Primary and Secondary eye care; Patient Safety and Quality of Care Improvements. This journal is indexed on Submit your manuscript here: http://www.dovepress.com/clinical-ophthalmology-journal

\section{Dovepress}

PubMed Central and CAS, and is the official journal of The Society of Clinical Ophthalmology (SCO). The manuscript management system is completely online and includes a very quick and fair peer-review system, which is all easy to use. Visit http://www.dovepress.com/ testimonials.php to read real quotes from published authors. 